\title{
High-resolution continental scale modelling of Australian wheat yield; biophysical and management drivers
}

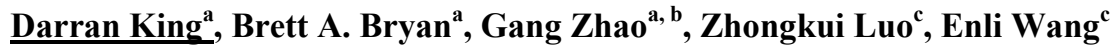 \\ ${ }^{a}$ CSIRO Ecosystem Sciences, Waite Road, Urrbrae, SA 5064, Australia \\ ${ }^{b}$ Institute of Geographic Science and Natural Resources Research, Chinese Academy of Sciences, 11 A Datun \\ Road, Anwai, Beijing 100101, China \\ ${ }^{c}$ CSIRO Land and Water, Black Mountain, Canberra, ACT 2601, Australia \\ Email: Darran.king@,csiro.au
}

\begin{abstract}
Production of cereal crops in Australia occurs in a specific envelope of biophysical attributes leading to suitable and non-suitable regions for cereal production. The geographic extent that this envelope encompasses is vast and varied. However, understanding the optimal conditions can only really be achieved through spatially and agronomically detailed studies of local biophysical attributes. Computational limitations and data burdens have limited the scope and resolution of studies in the past. We employed high performance grid computing and parallel programming to operationalise the Agricultural Production Simulation model (APSIM). We then simulate wheat production potential over 110 years across 180,000,000ha of arable land in Australia and statistically evaluate the results to determine the key drivers.
\end{abstract}

Analysis units were derived through a cluster evaluation of the primary climate and soil characteristics across an extended Australian cropping range. APSIM was used to generate simulated wheat production outputs for all locations over 110 years with 325 combinations of fertilization, tillage and residue treatments. Biophysical and management drivers were then examined for correlation using Spearman's Rho. Examinations of 3 management, 7 climate and 7 soil parameters (at 5 different soil depths) provided an indication of the strength and direction of each of these drivers on wheat yield. Based on the strength of the correlation, Nitrogen (N), Effective Rainfall in the Sowing to Harvest period (ER), Maximum Temperature in the Sowing to Harvest period (MTSH) and soil Water Holding Capacity (WHC) were found to be the key drivers of national scale wheat yield in Australia. Outputs were statistically validated against empirical data for similar fertilization, climate and soil characteristics in selected locations.

Results indicate that crop production varies considerably in space, time and in response to management action. Of the biophysical factors used in the model, ER between sowing and harvest exhibited a strong positive correlation with yield. This parameter also expressed the strongest correlation in any direction, at 0.64. Accumulated rain also returned a strong positive correlation with yield although it was considered a similar parameter to ER. Additionally the MTSH exhibited the strongest negative correlation with yield (0.34). The length of the growing season also demonstrated a positive correlation with yield (0.32). Fertilizer application was by far the management driver with the strongest correlation with yield at (0.53) whilst both residue removal and residue incorporation expressed weak negative (-0.04) and positive (0.02) correlations with yield respectively. No soil parameters demonstrated strong correlations with yield at any depth in the soil profile.

Results indicate that crop production varies considerably in space, time and in response to management action. Biophysical influences such as climate and soil exert an influence on yields with effective rainfall the key driver of production. An opportunity for farm managers to improve crop yields through careful management of fertilizer application in a small window where the marginal benefits of application change rapidly with other biophysical characteristics. These locations and timings require careful management so as to maximise yield without wasting resources. In all other times and locations the need for careful management is much less important as the relationships are largely unresponsive to one another. Like any study across large heterogeneous landscapes, considerable variations occur in the complex relationships between management and biophysical attributes. Understanding these complex relationships at a national scale is fundamental to sound future planning for issues of national importance such as climate change, soil carbon management and food security.

Keywords: $\quad$ Agricultural Production, Agricultural Production Simulation model (APSIM), Spatial 
King et al., High-resolution continental scale modelling of Australian wheat yield; biophysical and management drivers

\section{INTRODUCTION}

Understanding continental scale agricultural challenges such as climate change and food security requires accurate and detailed understanding of the management and biophysical conditions driving agricultural production systems vexed by spatial and temporal variability. Approaches to access this information in the past have varied from interpretation of real world census data to complex plant growth production models. However, when undertaken across very large geographic extents, the need to balance quantification of biophysical and management drivers with excessive detail (Adam et al., 2011) often leads to tradeoffs compromising the effectiveness of the results.

In this paper we make use of the vast idle computing capacity available in large organisations to circumvent computational limitations and statistically analyse high resolution agriculture production simulations at the national/continental scale. The single point Agricultural Production SIMulation model (APSIM) is passed through the Condor parallel computing environment to simulate the production of wheat across spatially homogenous climate and soil properties on a daily time step over 110 years. The model considered 325 variations of management actions including; 13 fertilizer (nitrogen) application rates, 5 levels of residue removal, and 5 levels of residue incorporation. Crop cultivars and sowing windows were matched to local conditions. We applied the model to the potential cereal cropping regions of continental Australia, divided into 11,575 homogenous spatial units. We evaluated the impact of biophysical drivers of soil and climate as well as management drivers of fertiliser and residue management on wheat yields across Australia and validate the outputs against census-reported production levels. Our implementation is novel in that the spatial and temporal resolution, geographic extent, and level of management detail is many times greater than ever before attempted-leading to new insights in the drivers and outcomes of agricultural production across Australia.

\section{METHODS}

\subsection{Study Area}

To define our study region (Figure 1), areas of existing cropping were aggregated from land use classes defined as 'irrigated and dry land sown pastures and crops' and 'irrigated sown crops and pastures' (ABARES, 2011) and buffered by $100 \mathrm{~km}$. A resulting region of approximately $\left(179 \times 10^{6} \mathrm{ha}\right)$ was defined as the potential cropping zone and as the study area.

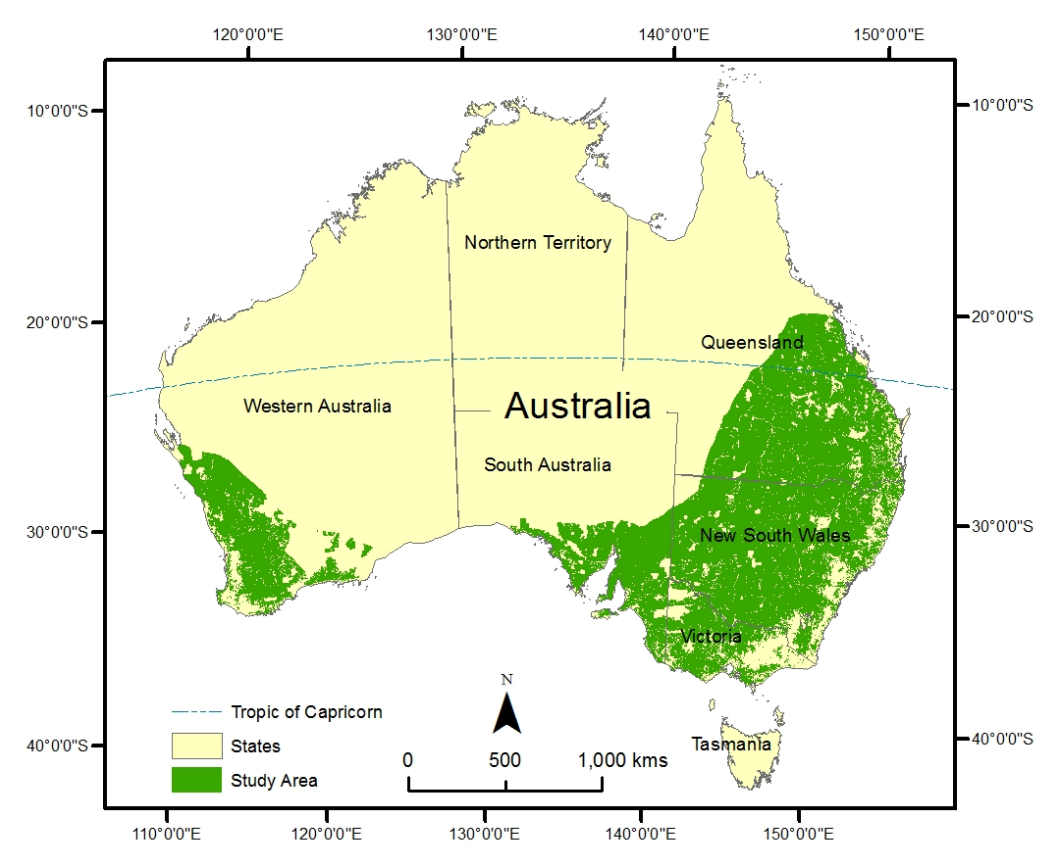

Figure 1 - Model study area 
King et al., High-resolution continental scale modelling of Australian wheat yield; biophysical and management drivers

\subsection{Climate-Soil Units}

Raster layers of climate clusters (35) were overlaid with Australian Soil Classification (ASC) classes (13) to create 382 homogeneous Climate Soil units (CS units) and 11,575 spatially-explicit parcels as the units of analysis. Post-processing was conducted in a Geographic Information System (GIS) to clean up vector overlay artefacts and fine-scale climate and soil input data was derived specifically for each of the 11,575 spatial units as the forthcoming units of analysis. Climate Soil units ranged in size from very small $(<1$ ha) to very large ( $>1$ million ha) with an average of 15,246 ha and a median size of 2,915 ha. Geographically the highest resolution mapping (smallest CS units) occurs in locations of more intense agricultural development where typically, more effort has been spent on detailed soil mapping.

\subsection{Crop Modelling}

The APSIM model version 7.3 including its Wheat, SoilN, SoilWater, and Surface Organic Matter modules has been demonstrated to perform well in simulating wheat crop growth, soil water dynamics, and soil nitrogen transformation under a variety of climatic, soil, and management conditions (Keating et al., 2003; Wang et al., 2003). Our model used APSIM to simulate annual continuous wheat systems from 1900 to 2010. The simulations included; 13 nitrogen (as urea) application rates between 0 and $300 \mathrm{~kg} \mathrm{ha}^{-1} \mathrm{yr}^{-1}$ at $25 \mathrm{~kg}$ increments with $25 \mathrm{~kg} \mathrm{~N} \mathrm{ha}^{-1}$ applied at sowing and the remainder at the stem elongation stage as a topdressing. Crop residue was retained at either $0,25,50,75$ or $100 \%$ of total standing biomass and could be incorporated into the top $20 \mathrm{~cm}$ of soil through tillage at $0,25,50,75$ or $100 \%$ of residue. Any residue not incorporated after harvest was removed.

\subsection{Biophysical and Management drivers}

Global Morans I was used to test the data's level of spatial autocorrelation. This test identifies if the pattern of an objects value and location in space is clustered or random. When objects with similar values occur in close proximity then the data is considered to be autocorrelated which can bias statistical models. Semivariograms graphically represent the strength of a variables correlation as a function of distance. As the distance between locations increases the strength of the correlation diminishes and the semivariogram curve begins to flatten. Beyond this inflection point, known as the range, the data is no longer considered to be spatially autocorrelated. Given the considerable variation in the size of CS units, the number required to avoid spatial autocorrelation was identified through randomly selecting and examining samples. Samples of $500 \mathrm{CS}$ units exhibited sufficiently small variation in the squared difference of yield pairs over increasing distances of separation to be a suitable sample size for statistical examination. Bivariate scatter plots of model parameters were then examined to determine the linearity of the data and the subsequent suitability of various correlation techniques. Given the nonlinear but monotonic nature of the scatter plots, Spearman's Rho was chosen as the most robust test of correlation.

An initial examination of 3 management, 7, climate and 7 soil parameters (at 5 different soil depths) provided an indication of the strength and direction of each of these drivers on wheat yield. Any drivers with correlation results between 0.15 and -0.15 were excluded from further analysis and a subjective select/reject of the remaining parameters was undertaken based on the similarity and strength of the remaining parameters. Nitrogen (N), Effective Rainfall in the Sowing to Harvest period (ER), Maximum Temperature in the Sowing to Harvest period (MTSH) and soil Water Holding Capacity (WHC) were the key drivers that represent national scale wheat yield. These drivers were then graphed in bivariate contour plots and their relationships and effects analysed. Unlike ER, MTSH and WHC, $\mathrm{N}$ has spatial and temporal uniformity in the model. Changes in $\mathrm{N}$ application are modified exogenously and then interact with other parameters in time and space to produce long term average yields hence, $\mathrm{N}$ applications were assessed for spatial variation through regression with yield holding all other parameters constant.

\subsection{Validation}

We compared 2006 simulated yields with reported yields from the Australian Bureau of Statistics for the same year. $\mathrm{N}$ application rates from were obtained from Gross Margin (GM) handbooks for selected regions and applied to the existing modelling. Using a student's t-test, simulated yields were compared to the ABS reported yields across the three sample regions including the West Australian wheat belt, the South Australian and western Victorian cropping districts, and northern New South Wales. 
King et al., High-resolution continental scale modelling of Australian wheat yield; biophysical and management drivers

\section{RESULTS}

Simulated long term average wheat yields ranged from 8 to $3324 \mathrm{~kg} \mathrm{ha}^{-1} \mathrm{yr}^{-1}$ with a national average of 554 $\mathrm{kg} \mathrm{ha}^{-1} \mathrm{yr}^{-1}$ at $0 \mathrm{~kg} \mathrm{ha}^{-1} \mathrm{yr}^{-1} \mathrm{~N}$ application and complete residue removal. The major cropping districts in south-central Australia and the wheat belt of south-western Australia were the highest-yielding regions, where some areas produced yields as high as $7892 \mathrm{~kg} \mathrm{ha}^{-1} \mathrm{yr}^{-1}$ in the best years with optimised management. Conversely, the central region of the study area was the poorest performer, with low average yields and in the worst years, complete crop failure. The best performing regions were also subject to the greatest range of variation as very high yields were returned in good years and crops performed poorly in other years.

Effective Rainfall ranged from $27 \mathrm{~mm} \mathrm{yr}^{-1}$ to $523 \mathrm{~mm} \mathrm{yr}^{-1}$ with the low ER values occurring in the more interior locations with a clear banding of geographic distribution as ER increases with a reduction in proximity to the coast. MTSH followed a similar geographic distribution to ER. The lowest long term average MTSH's of $10{ }^{\circ} \mathrm{C}$ occur in the most southerly regions of the country while the highest $\left(29{ }^{\circ} \mathrm{C}\right)$ in the northern most regions. The banding is less evident in MTSH than ER but the general trend from inland and northern locations to coastal and southern locations is evident. Long term average WHC ranged from 0.02 $\mathrm{mm} \mathrm{m} \mathrm{m}^{-1}$ to $0.26 \mathrm{~mm} \mathrm{~mm}^{-1}$. The highest WHC's occur in the central eastern region of the study area while the lighter sandier soils of the west exhibit much lower WHC. Spatially the yield benefits per kg ha-1 $\mathrm{yr}^{-1}$ of nitrogen added ranged from 10.8 to $42.8 \mathrm{kgs}^{-1} \mathrm{ha}^{-1} \mathrm{yr}^{-1}$ with a national average of $21 \mathrm{kgs}^{-1} \mathrm{ha}^{-1} \mathrm{yr}^{-1}$.

\subsection{Drivers of wheat yield}

Of the biopysical factors used in the model, ER exhibited a strong positive correlation with yield (Error! Reference source not found.). This parameter also expressed the strongest correlation in any direction at (0.56). Accumulated rain also returned a strong positive correlation with yield although it was considered a similar parameter to ER. Additionally the MTSH exhibited the strongest negative correlation with yield (0.34). The length of the growing season also demonstrated a positive correlation with yield (0.32). Fertilizer application was by far the management driver with the strongest correlation with yield at (0.53) whilst both residue removal and residue incorporation expressed weak negative $(-0.04)$ and positive $(0.02)$ correlations with yield respectively. No soil parameters demonstrated strong correlations with yield at any depth in the soil profile although soil WHC produced the strongest correlation with yield throughout the profile and the strongest correlation ( 0.22 at layer 4$)$ of any soil parameter anywhere through the profile.

Table 1 - Results of the spearman's rank correlation test for a selected set of parameters

\begin{tabular}{llc}
\hline & Parameter & Spearman's Rho \\
\hline \multirow{3}{*}{ Management } & $\mathbf{0 . 5 2 7}$ \\
& Fertilization & -0.040 \\
& Residue removal & 0.023 \\
\hline \multirow{4}{*}{ Climate } & Residue incorporation & 0.322 \\
& Days from sowing to harvest & $\mathbf{- 0 . 3 3 5}$ \\
& Average Maximum temperatures from sowing to harvest & -0.230 \\
& Average Minimum temperatures from sowing to harvest & 0.158 \\
& Accumulated solar radiation from sowing to harvest & $\mathbf{0 . 5 5 8}$ \\
\hline \multirow{4}{*}{ Soil } & Effective Rainfall from sowing to harvest & -0.044 \\
& Depth of soil layer (layer 4) & -0.110 \\
& Soil bulk density (layer 4) & 0.070 \\
& Soil ph (layer 4) & $\mathbf{0 . 2 2 4}$ \\
\hline
\end{tabular}

Fertilizer application, ER and WHC all demonstrated a positive relationship with yield while MTSH produced a negative relationship. At very low levels of fertilizer application $\left(<25 \mathrm{~kg} \mathrm{ha}^{-1} \mathrm{yr}^{-1}\right)$, the benefits of additional $\mathrm{N}$ were significant and effective across all locations. With increased fertilizer application additional benefits continue to be realised although the marginal benefits diminish across all locations. ER is also significant and effective across all locations. Large yield gains were observed in the modelling in response to relatively small increases in ER. Response to ER shifted at 400mm where the marginal benefits of an increase in ER significantly reduced. WHC at layer four of five in the soil profile produced a similar 
King et al., High-resolution continental scale modelling of Australian wheat yield; biophysical and management drivers

yield response to that of fertilizer application with diminishing marginal benefits of greater water holding capacities. MTSH demonstrated an inflection point where the marginal cost of increased temperature on yield was smaller at maximum temperatures ( $\mathrm{SH})$ above $22^{\circ} \mathrm{C}$.

Bivariate contour plots (Figure 2) demonstrated the combined effect on wheat yields between four of its most influential drivers. Fertilizer application and MTSH were negatively associated at fertilizer application rates above $50 \mathrm{~kg} \mathrm{ha}^{-1} \mathrm{yr}^{-1}$. The influence of MTSH was greater in the lower ( $5^{\text {th }}$ percentile $)$ than in the higher $\left(95^{\text {th }}\right.$ percentile) yields. Fertilizer application and ER had similar effects on yield to fertilizer application and WHC. Both demonstrate positive relationships with yield at fertilizer application rates above $50 \mathrm{~kg} \mathrm{ha}^{-1} \mathrm{yr}^{-1}$, ER above $200 \mathrm{~mm} \mathrm{yr}^{-1}$ or water holding capacities above $0.12 \mathrm{~mm} \mathrm{~mm}^{-1}$. Fertilizer application and WHC at the $5^{\text {th }}$ percentile produced yield at levels below $1000 \mathrm{~kg} \mathrm{ha}^{-1} \mathrm{yr}^{-1}$ only.
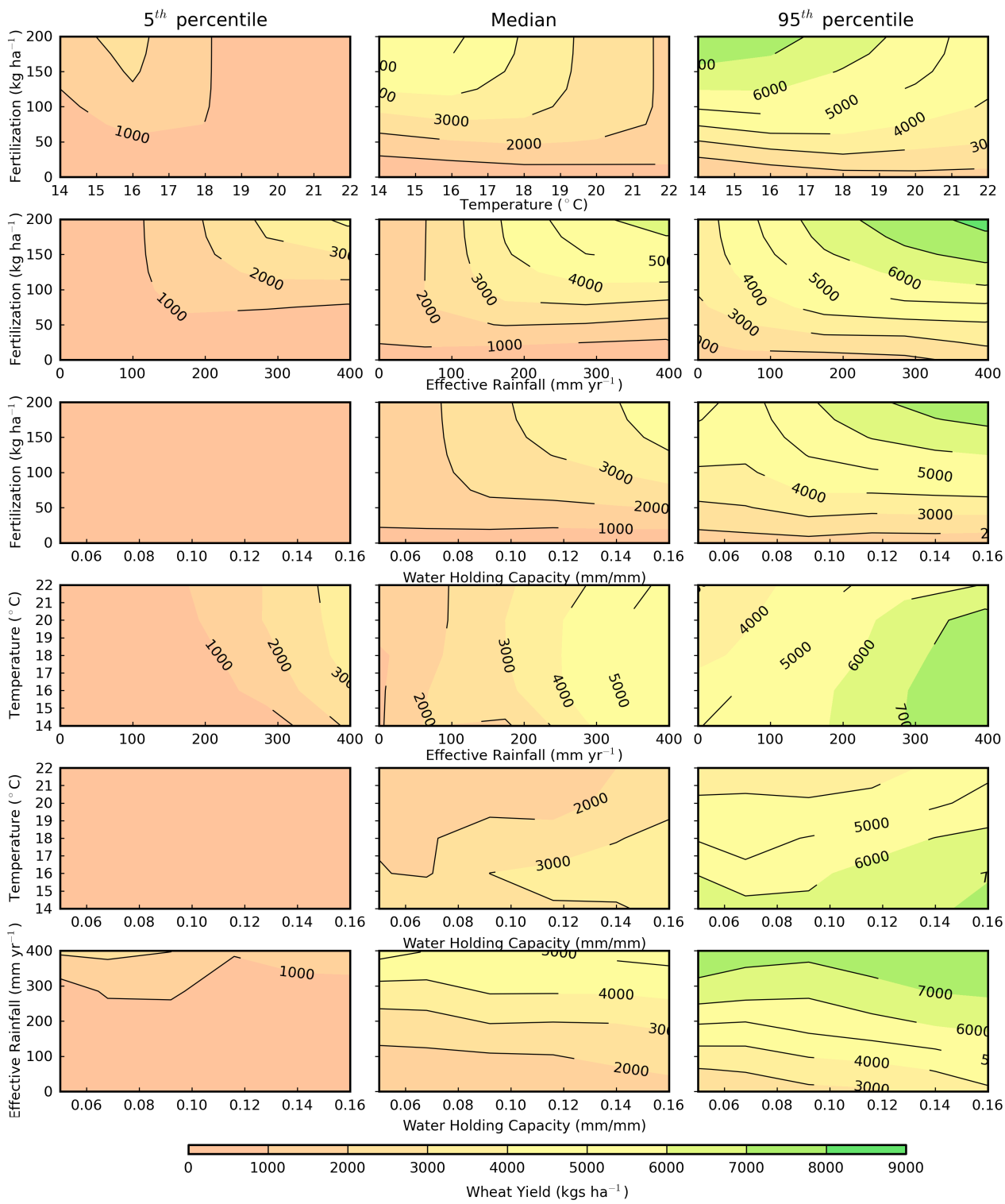

Figure 2 - Bivariate contour plots of the four key drivers of wheat yield

The combined effects of MTSH and ER was markedly different between each of the three percentile yield levels. At the lower $5^{\text {th }}$ percentile MTSH and ER exhibit a positive relationship while at the $95^{\text {th }}$ percentile this relationship becomes negative. For the median level the relationship is negative at MTSH levels below $16{ }^{\circ} \mathrm{C}$ and ER above $100 \mathrm{~mm} \mathrm{yr}^{-1}$. Between $16^{\circ} \mathrm{C}$ and and $20{ }^{\circ} \mathrm{C} \mathrm{ER}$ is the dominant driver while above $20{ }^{\circ} \mathrm{C}$ the relationship becomes positive. MTSH and WHC exhibit a slightly negative relationship while WHC and ER produce a slightly positive relationship although in both cases WHC produces limited effect. 
King et al., High-resolution continental scale modelling of Australian wheat yield; biophysical and management drivers

\section{CONCLUSION}

We employed high performance grid computing and parallel programming to operationalise the crop model APSIM to simulate crop (wheat) production potential over 110 years across 180,000,000ha of arable land in Australia. The model produced crop production estimates across space, through time and, across various management decisions. Results indicate that crop production varies considerably in space, time and in response to management action. Biophysical influences such as climate and soil exert an influence on yields with effective rainfall the key driver of production. More generally the results indicate that tillage and residue retention do not show up as a strong indicators for production although others have found considerable benefits for soil organic carbon (Zhao etal 20013). The model indicates that an opportunity for farm managers to improve crop yields through careful management of fertilizer application. A small fertilization window exists where the marginal benefits of application change rapidly with other biophysical characteristics. These locations and timings require careful management so as to maximise yield without wasting resources. In all other times and locations the need for careful management is much less important as the relationships are largely unresponsive to one another. Like any study across large heterogeneous landscapes, considerable variations occur in the complex relationships between management and biophysical attributes. Understanding these complex relationships at a national scale is fundamental to sound future planning for issues of national importance such as climate change, soil carbon management and food security.

\section{REFERENCES}

ABARES, (2011) Guidelines for land use mapping in Australia: principles, procedures and definitions, Fourth edition ed, Canberra.

Adam, M., Van Bussel, L.G.J., Leffelaar, P.A., Van Keulen, H., Ewert, F. (2011) Effects of modelling detail on simulated potential crop yields under a wide range of climatic conditions. Ecological Modelling 222, 131143.

Keating, B.A., Carberry, P.S., Hammer, G.L., Probert, M.E., Robertson, M.J., Holzworth, D., Huth, N.I., Hargreaves, J.N.G., Meinke, H., Hochman, Z., McLean, G., Verburg, K., Snow, V., Dimes, J.P., Silburn, M., Wang, E., Brown, S., Bristow, K.L., Asseng, S., Chapman, S., McCown, R.L., Freebairn, D.M., Smith, C.J. (2003) An overview of APSIM, a model designed for farming systems simulation. European Journal of Agronomy 18, 267-288.

Wang, E., Robertson, M.J., Hammer, G.L., Carberry, P.S., Holzworth, D., Meinke, H., Chapman, S.C., Hargreaves, J.N.G., Huth, N.I., McLean, G. (2003) Development of a generic crop model template in the cropping system model APSIM. European Journal of Agronomy 18, 121-140.

Zhao G, Bryan B A, King D, Luo Z K, Wang E L, Song X D and Yu Q 2013b Impact of agricultural management practices on soil organic carbon: simulation of Australian wheat systems Global Change Biol. $191585-97$ 